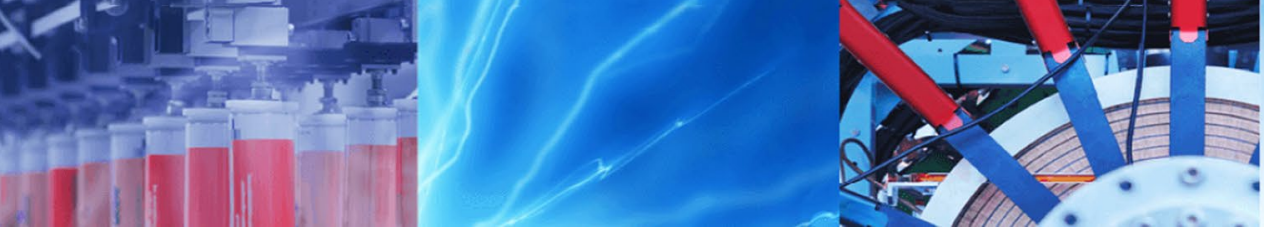

Research Article

\title{
Reliability assessment of RC frames rehabilitated by eccentrically braces having vertical shear link
}

\author{
S. Safaei ${ }^{1} \cdot$ H. Naderpour ${ }^{1}$ (D) M. Gerami ${ }^{1}$
}

Received: 5 January 2020 / Accepted: 17 February 2020 / Published online: 22 February 2020

(c) Springer Nature Switzerland AG 2020

\begin{abstract}
A considerable number of existing reinforced concrete (RC) structures need to seismic rehabilitation due to several reasons such as being designed just based on gravity loading and/or having an unsatisfactory level of ductility. One of the types of steel bracing can be referred to eccentrically braced frames with a vertical link. This system has some advantages such as an increase in ductility, stiffness and lateral strength, the ability to adapt to the architecture, and also the minimum weight added to the structure. In this study, reliability analysis assessment of two existing 3-, and 9-story RC frames in two cases including original and rehabilitated with an eccentrically braced frame having a vertical link is presented. Two limit states are defined as: maximum roof displacement and maximum inter-story displacement. The seismic behavior of frames was assessed by nonlinear static pushover analysis with finite element program OpenSees in two performance levels, including collapse prevention and life safety. Five random variables represented the variability in resistance of concrete material, bars and steel profiles yield stress, beams height, columns dimension, and also bars cross-section. Sensitivity analysis was carried out to recognize the effect of random variables on the reliability index. The reliability analysis was performed by two different methods: Hasofer-Lind and Monte Carlo with 25, 100, 1000, 10,000 and 100,000 simulated samples by considering two distributions including Normal and Log-Normal. Finally, a comparison between two common reliability methods was carried out in order to select the most appropriate method for performing the best seismic performance reliability analysis of $\mathrm{RC}$ frames rehabilitated by the proposed system.
\end{abstract}

Keywords Reliability $\cdot$ Reinforced concrete $\cdot$ Eccentrically braced frame $\cdot$ Monte Carlo $\cdot$ Hasofer-Lind

\section{Introduction}

The possibility of severe earthquakes occurrence due to natural geology conditions on the one hand, and the design and construction of many RC buildings in which seismic loading criteria are not considered, or their seismic loads are underestimated because of changes in these criteria on the other hand would result in necessity of seismic evaluation and rehabilitation $[6,39,40]$. Recent earthquakes around the world have shown that non-ductile (gravity load-designed) reinforced concrete (RC) buildings are vulnerable to severe damage or complete collapse. The application of eccentrically braced frames with a vertical link in seismic rehabilitation, not only eliminates the possible buckling of braces, but also leads to large inelastic deformations reduction which is applied to RC members. Hence, this research is focused on the seismic performance reliability analysis of RC frames which is rehabilitated by eccentrically braced frame with a vertical link, which is able to dissipate the earthquake input energy without buckling of the braces and the minimum damage of RC members.

In the last decade, there are important efforts to retrofit the reinforced concrete elements. Seismic behavior of steel moment resisting frames associated with $\mathrm{RC}$ shear walls were investigated by Esmaeili et al. [11]. Naderpour et al. [30] predicted the FRP-confined compressive strength of

H. Naderpour, naderpour@semnan.ac.ir | ${ }^{1}$ Faculty of Civil Engineering, Semnan University, Semnan 3513119111, Iran.

SN Applied Sciences (2020) 2:466 | https://doi.org/10.1007/s42452-020-2288-0 
concrete. Ahmadi et al. [3] presented a model for predicting the compressive strength of circular steel-confined concrete. Compressive strength of environmentally friendly concrete was investigated by Naderpour et al. [31]. Furthermore, Ahmadi et al. [4] studied the seismic failure probability and vulnerability assessment of steel-concrete composite structures. Shear failure capacity prediction of concrete beam-column joints and classification of failure modes in ductile and non-ductile concrete joints were also studied [28, 29]. Haji et al. [14] performed an experimental study on influence of proposed FRP-strengthening techniques on RC circular short columns considering different types of damage index. Finally, Moradi et al. [26] conducted an experimental approach for shear strengthening of RC beams using a proposed technique by embedded through-section FRP sheets.

The most appropriate approach for evaluating the influence of earthquake-resistant structural system becomes possible with reliability analysis, because reliability analysis can easily reflect the uncertainties which exist in seismic loading and structure capacity. Seismic performance assessment based on reliability is performed by using the information obtained from past earthquakes investigation $[27,33]$. Therefore, for seismic performance reliability assessment, the full coupling between a finite element analysis and common reliability methods such as the Monte Carlo simulation method (MC) and Hasofer-Lind should be used. Reliability-based finite element method (RFEM) tends to be high computational and time-consuming for practical problems. This is because, at any iteration, the limit-state function and its derivatives are to be evaluated through finite element computations. To solve the problems associated with the finite element full coupling reliability analysis, the response surface-based method (RSM) was introduced by Khuri and Cornell [18]. This method enables us to fit the structural response such as stresses or displacements in terms of random variables for reliability analyses.

In the study of Lou et al. [19], two flat slab buildings, three and 10 stories in height, designed according to the $\mathrm{ACl}$ 318-56 building code, were used in the nonlinear dynamic analysis and reliability calculations. The member dimensions, material strengths, and live load were treated as random variables and the effect of model uncertainty was included in the calculations of reliability indices. The limit-state function was based on the punching failure capacity of the interior slab-column connections. Huh and Haldar [16] used a proposed algorithm for reliability assessment of a steel building under the seismic loads, this algorithm concluded response surface method, finite element method, first-order reliability method and linear interpolation. Their research by considering serviceability limit states showed that the maximum drift is more critical than the total drift of the structure under seismic excitation. Hadianfard and Razani [13] presented a study for semi-rigid connections of steel frames using the finite element analysis and reliability analysis. The loads and resistance of members were selected as the random variables. The Monte Carlo simulation technique was used to calculate the probability of failure of the steel frame. It was concluded that semi-rigid connections should be considered for steel frames for more realistic and reliable results. The goal of the research conducted by Marinilli [21] was to perform a simplified stochastic analysis of reinforced concrete frames under seismic loads. Simplified analyses were performed based on the point estimate method (PEM), considering compressive concrete strength $\left(f_{c}{ }^{\prime}\right)$ and reinforcement steel yield stress $\left(f_{y}\right)$ as independent stochastic variables. Jalayer et al. [17] examined the influence of structural modeling uncertainties on the assessment of existing $R C$ structures through a relatively simple response spectrum based method, and verified the codebased requirements with regard to the confidence factors. Abdelouafi et al. [1] were focused on the seismic performance reliability analysis of a 5 story concrete building by regarding three random variables which are characterizing material resistance variations of concrete and reinforcement steel as well as member's sections dimensions. In this research two limit states defined in terms of the total building roof displacement and the maximum inter-story drift were considered and for seismic performance reliability analysis two approximate methods: Monte Carlo based sampling analysis and first-order reliability method (FORM) was performed. In the study of Basaga et al. [5], the reliability analysis of the four and eight stories, consisting of a portal frame and three types of concentrically braced frames with semi-rigid connections is presented. The direct coupling method, which is a combination of the reliability method such as FORM and Monte Carlo and finite element method, is utilized to determine the reliability indexes and probabilities of failure for the structure. Results showed that $\mathrm{X}$ braced frames are determined as the safest structures, while the portal frames are regarded as the most unsafe structures. As the connection percentage increases, the safety of the structure increases. In the study of Celarec and Dolsek [7] the impact of modeling uncertainties on the seismic performance assessment of reinforced concrete frame buildings was investigated. In their research the effects of the epistemic uncertainty are treated by using the first-order second-moment (FOSM) method, and the Latin hypercube sampling (LHS) technique. At least, explicit consideration of epistemic uncertainties in the process of the assessment of structural performance can lead to more accurate results, and consequently also to a more reliable assessment of seismic risk. 
The aim of this work is to apply the response surfacebased reliability analysis methodology to evaluate the seismic performance of reinforced concrete frames rehabilitated by eccentrically bracing. The effects of variations resulting from loading will be overlooked and the focus will be towards the effects resulting from the building structure's geometric dimensions and from durability problems that affect the mechanical properties of reinforced concrete materials, specifically the characteristic value of the concrete resistance and the nominal yielding point of steel reinforcement and profiles. A comparison between results obtained by the Monte Carlo sampling method and the Hasofer-Lind method will be performed by regarding two probability distribution Normal and Lognormal in order to model the random variables. The discussion will be carried out in order to select the appropriate method that can be used to evaluate the reliability of RC frames which is seismically rehabilitated by eccentric bracing with a vertical link.

\section{RC frame with eccentric bracing with vertical link}

The RC Frame with eccentric bracing with a vertical link, as shown in Fig. 1, can be applied in various configurations such as: (a) the shear link and the braces are directly connected to the $\mathrm{RC}$ members via steel plates, bolts and epoxy grouting (see PSRM-1), (b) the shear link is connected to a collector steel beam attached to the concrete beam and the rest of the members are connected to the RC members via steel plates, bolts and epoxy grouting (see PSRM-2) or (c) the shear link and the braces are housed in a rectangular steel frame (housing frame) where the steel frame is connected to the RC members by bolts and epoxy grouting (see PSRM-3). In this work the (a) configuration is used as a proposed seismic rehabilitation system since it is easy in construction and widespread in the executive application as well as reduces the time and cost of erecting.

\section{Basics of reliability methods}

In the reliability theory, the probability of exceeding a limit state is studied in which the limit state is defined by a mathematic function called limit state function that is based on the design parameters. The limit state function divides the data space into two regions: safe and failure regions. The safety of structures is determined by two parameters of the reliability index $(\beta)$ and failure probability $\left(P_{f}\right)$. So many techniques are available for performing reliability analysis in order to obtain the mentioned parameters. In the following, two common ways of expressing their basic concepts are introduced.

In [15], Hasofer and Lind defined the reliability index of a structure in standard Normal space as the shortest distance from the origin of the coordinate system to the failure point (design point). The Hasofer-Lind reliability analysis method is considered as the first-order approximation of the Taylor series for limit state functions. According to Fig. 2, the design point is a point on the failure surface $\mathrm{g}=0$. Since this design point is not known completely, a
Fig. 1 Details and configurations of RC frame with eccentric bracing with vertical link

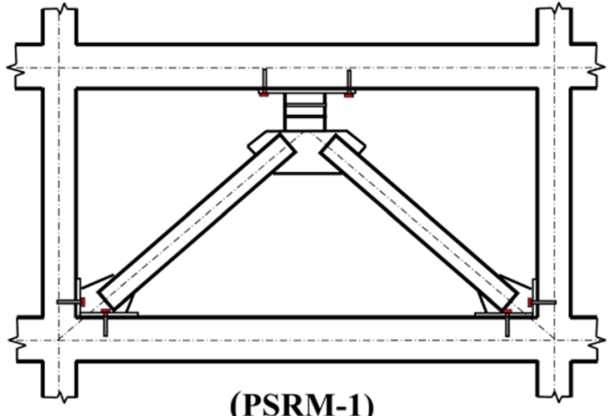

(PSRM-1)

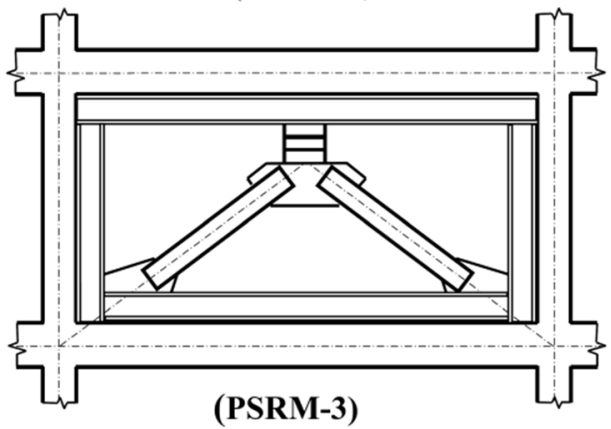

(PSRM-3)

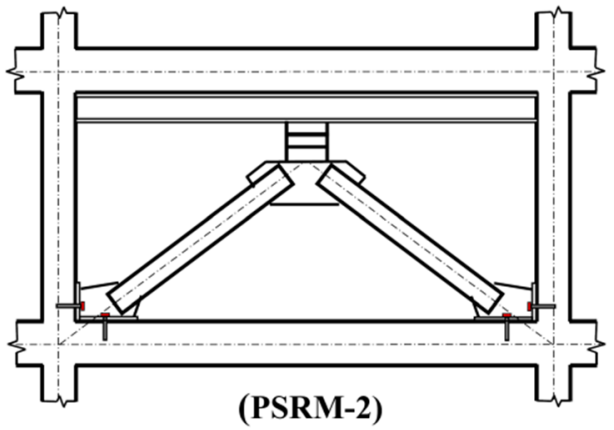

(PSRM-2)

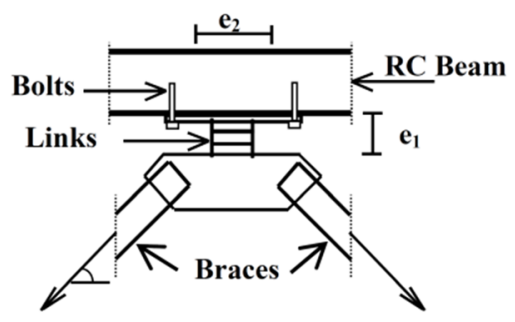




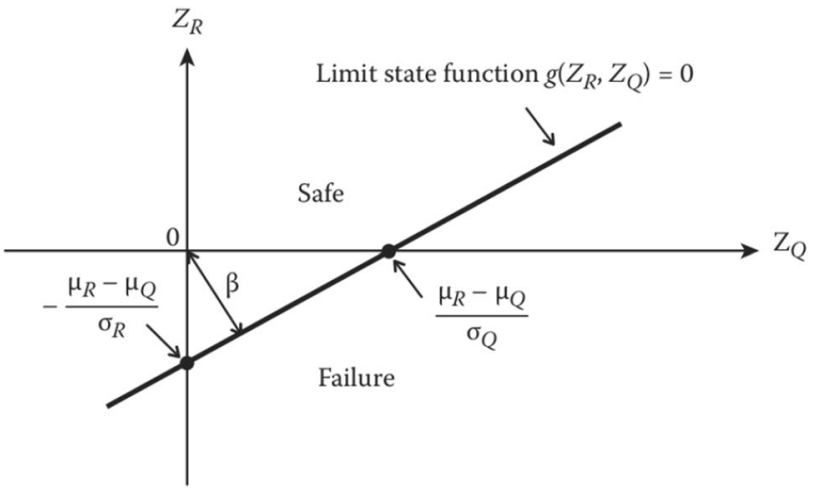

Fig. 2 Reliability index defined as the shortest distance from the origin of the coordinate system to the failure point [32]

repeated process is used to reach the desired reliability index $(\beta)$. Based on the geometry, the reliability index (shortest distance) can be introduced by $\beta=\frac{\mu_{R}-\mu_{Q}}{\sqrt{\sigma_{R}{ }^{2}+\sigma_{Q}{ }^{2}}}$ in which $\mu_{R}$ and $\mu_{Q}$ represent the mean value of resistance and demand respectively and also $\sigma_{R}$ and $\sigma_{Q}$ represent the standard deviation of resistance and demand respectively. Then the probability of failure $\left(P_{f}\right)$ is determined as $P_{f}=\phi$ $(-\beta)$ in which $\phi$ is the cumulative distribution of standard Normal variable (Fig. 2).

Monte Carlo simulation method, similar to a computer laboratory, simulates the test on the computer. In this method, random values would be generated for each random variable based on the distribution type and statistic parameters such as mean and standard deviation and so the limit state function associated with these values are obtained. A negative value of limit state means that the limit state is not satisfied and the failure of the system occurs. The failure probability (PF) is then calculated by dividing the number of times that the limit state is negative by a total number of simulated tests on the computer.

Expressing the limit state function as $G(X)$, where $\mathrm{X}=\left(\mathrm{X}_{1}, \mathrm{X}_{2}, \ldots, \mathrm{X}_{\mathrm{n}}\right)$ is the vector of the basic random variables, the probability of failure can be determined using the below relationship.

$P F=\int_{G(X) \leq 0} f_{x}(X) d X$

where $f_{X}(X)$ is the joint probability and $G(X)$ is an irregular domain with highly non-linear boundaries. Following the law of large numbers, an unbiased estimator of the probability of failure is given by

$\overline{\mathrm{PF}}=\frac{1}{\mathrm{~N}} \sum_{\mathrm{i}=1}^{\mathrm{N}} \mathrm{I}\left(\mathrm{X}_{\mathrm{i}}\right)$

where I (Xi) is an indicator defined as:
$I\left(X_{i}\right)=\left\{\begin{array}{l}1 \text { if } G\left(X_{i}\right) \leq 0 \\ 0 \text { if } G\left(X_{i}\right)>0\end{array}\right.$

Accordingly, $\mathrm{N}$ independent random samples of a specific probability density function of the vector $\mathrm{X}$ are prepared and the failure function is computed for each sample $\mathrm{Xi}$. If $G\left(X_{i}\right) \leq 0$ a successful simulation is counted. The Monte Carlo estimate of the probability of failure $\left(P_{f}\right)$ can then be expressed in terms of the sample mean as

$\overline{\mathrm{PF}}=\frac{\mathrm{N}_{\mathrm{H}}}{\mathrm{N}}$

where $N_{H}$ is the number of successful simulations and $N$ is the total number of simulations [13].

Since this technique is so time to consume and expensive and also needs so much volume for performing, the approximate methods for reliability analysis like Hasofer-Lind are preferred [14].

\section{Numerical study}

\subsection{Details of frames}

Analytical models to evaluate RC frame with eccentric bracing with a vertical link, are two office non-ductile RC frames, 3 and 9 stories, that are designed based on gravity load [9] according to the $\mathrm{ACl}$ code [2]. The design concrete strength is $21 \mathrm{MPa}$ and the design steel strength is $300 \mathrm{MPa}$ and the modulus of elasticity is $200,000 \mathrm{MPa}$. The design dead load and live load for the frames are considered respectively $35 \mathrm{kN} / \mathrm{m}^{2}$ and $12 \mathrm{kN} / \mathrm{m}^{2}$. The frames mass due to the weight of all structural and nonstructural elements are equal to $945 \mathrm{~kg} /$ floor. The structural details of the frames are given in Table 1.

\subsection{Design}

For the seismic rehabilitation design of these frames, a performance-based approach is used. The performancebased approach is based on the objective performance level in order to encounter different probabilistic earthquakes. The objective performance levels (PLs) which are used to design the proposed seismic rehabilitation system are: Life Safety (LS) building performance level for the BSE-1 earthquake hazard level (10\%-in-50-year probability of exceedance or 474-year return period) and collapse prevention (CP) building performance level for the BSE-2 earthquake hazard level (2\%-in-50-year probability of exceedance or 2475 year return period). In FEMA 356 [12], the acceptance criteria for the mentioned PLs are mainly defined by the plastic rotation limits of the $\mathrm{RC}$ members. In 
Table 1 Structural details of 3and 9-story RC buildings

\begin{tabular}{|c|c|c|c|c|c|c|c|}
\hline \multirow[t]{2}{*}{ Story } & \multicolumn{2}{|c|}{ Exterior column } & \multicolumn{2}{|c|}{ Interior column } & \multicolumn{3}{|c|}{ Interior beam } \\
\hline & Size $^{a}$ & Steel $^{b}$ & Size & Steel & Size & Top steel & Bottom steel \\
\hline \multicolumn{8}{|c|}{3 story } \\
\hline $1-3$ & $30 \times 30$ & $4 \Phi 19$ & $40 \times 50$ & $8 \Phi 19$ & $25 \times 60$ & $5 \Phi 19$ & $2 \Phi 19$ \\
\hline \multicolumn{8}{|c|}{9 story } \\
\hline $1-3$ & $50 \times 50$ & $8 \Phi 22$ & $60 \times 60$ & $8 \Phi 25$ & $25 \times 60$ & $5 \Phi 19$ & $2 \Phi 19$ \\
\hline $4-6$ & $40 \times 40$ & $8 \Phi 19$ & $50 \times 50$ & $8 \Phi 22$ & $25 \times 60$ & $5 \Phi 19$ & $2 \Phi 19$ \\
\hline $7-9$ & $30 \times 30$ & $4 Ф 19$ & $40 \times 50$ & $8 \Phi 19$ & $25 \times 60$ & $5 \Phi 19$ & $2 \Phi 19$ \\
\hline
\end{tabular}

$\Phi$ (Diameter; $\mathrm{mm}$ )

${ }^{\text {a }}$ All measurements are in millimeters

${ }^{b}$ Number of reinforcement order to design the seismic rehabilitation details of frames, a technique based on performance is used that is mainly associated with the equal energy dissipation principle. In this method, the monotonic energy dissipation capacities of the frames in the linear elastic range based on the roof displacement obtained from response spectrum (RS) analyses and in the nonlinear inelastic range obtained from NLSP analyses for each PL are calculated and compared with each other. The difference between the areas under base shear force versus roof displacement curves in the elastic and inelastic cases is equal to the additional energy that needs to be absorbed by the RC frame with eccentric bracing with a vertical link [8]. The arrangement of the seismic rehabilitation system in the frames view is shown in Fig. 3. Also, braces and shear links details of probabilistic seismic response model (PSRM) for frames are available in Table 2.

\subsection{Modeling}

Numerical models of frames were formed by using the 2D modeling capabilities of OpenSees [34]. Nonlinear behavior distribution along the length and cross-section of the element is modeled completely and this causes in the failure distribution. The connections of all frames members except the shear link are considered to be rigid. In order to model pinned joints for both ends of braces, a "zero Length" element with high rigidity just in the transition directions was used. In dynamic computations according to the assumption of the rigid diaphragm in roofs,
Fig. 3 View of RC frames rehabilitated by eccentric bracing with vertical link

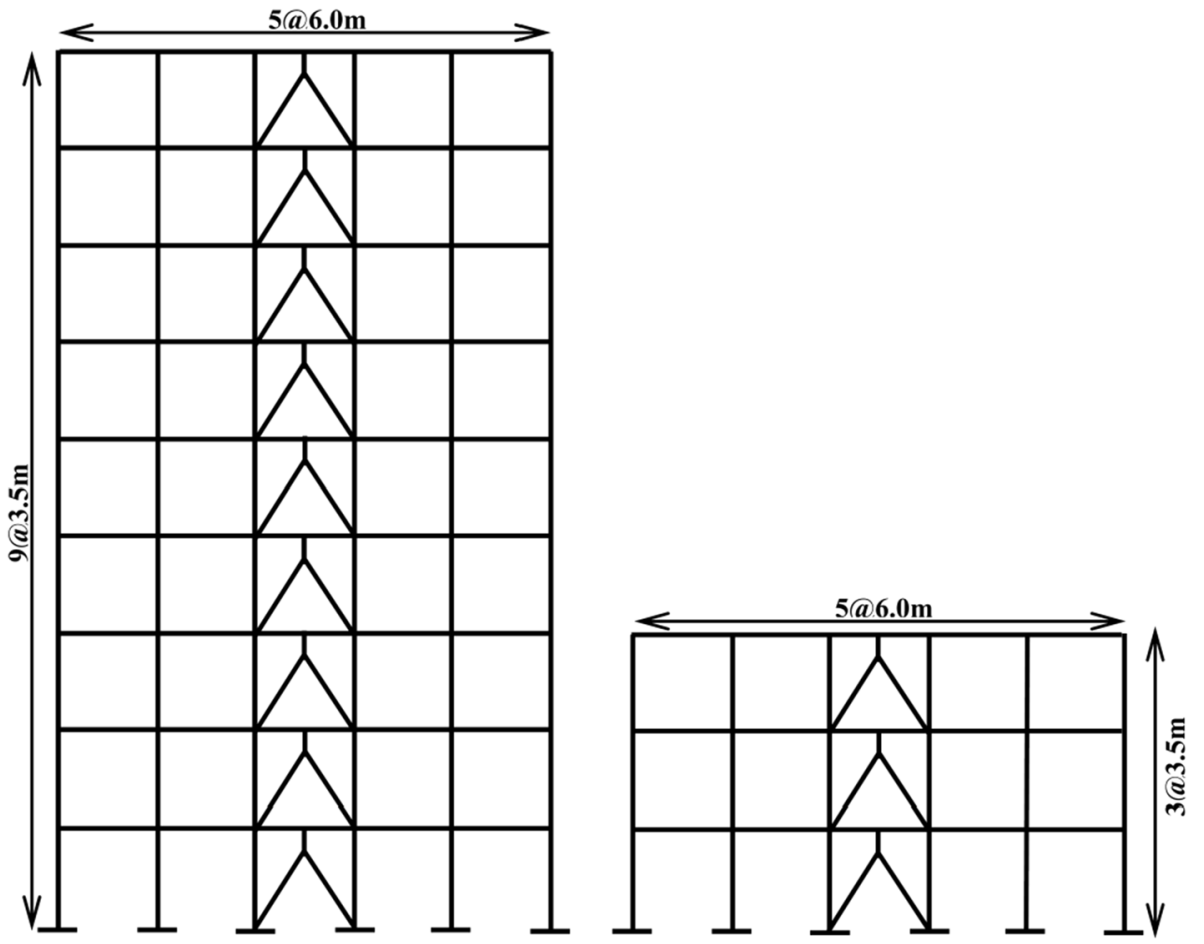

SN Applied Sciences a SPRINGer NatURE journa 
Table 2 Details of PSRM for 3 and 9 story for RC frames

\begin{tabular}{llll}
\hline Story & Braces & \multicolumn{2}{l}{ Single-VL (vertical link) } \\
\cline { 3 - 4 } & Section & Section & $\mathrm{e}_{1}(\mathrm{~cm})$ \\
\hline 3 story & & & \\
1 & 2 UNP140 & IPE400 & 82 \\
2 & $2 U N P 120$ & IPE360 & 76 \\
3 & $2 U N P 120$ & IPE330 & 70 \\
9 story & & & \\
$1-3$ & $2 U N P 140$ & IPE450 & 86 \\
$4-6$ & $2 U N P 140$ & IPE400 & 76 \\
$7-9$ & $2 U N P 120$ & IPE360 & 70 \\
\hline
\end{tabular}

stories mass in the height of stories are equally distributed between the nodes which are connected to the beam and column. The command of "Concrete 01 " is used to define concrete material including confined and unconfined concrete and the command of "steel 02 " is used to define the steel material. In order to model beam, column, and brace elements in the OpenSees "non-linear Beam-Column" is used and is divided into five sections. All the sections are modeled by the "Fiber" model. The assigned damping to the elements and nodes is modeled by the command of "Rayleigh". By assuming a small eccentricity, the buckling of braces is also taking into the account. Besides, $\mathrm{P}-\Delta$ effects are considered [35].

Ramadan and Ghobarah [36] modeled the shear link as a linear element with six nonlinear rotational and translational springs at each end. So that 3 rotational bilinear springs and 3 translational bilinear springs were used to represent respectively inelastic behaviors of the flexural plastic hinge and shear of the web link at the end of the link. The selected model in this paper is the Richards model [37] that is the same model of Ramadan and Ghobarah but with different stiffness values for the shear springs. The values of $M_{y}$ and $V_{y}$ are equal to $M_{p}$ and $0.9 V_{p}$ respectively. The relationships of flexure-rotation and shear-displacement of the shear link with their stiffness values are shown in Fig. 4. The values of $\mathrm{K}_{1 \mathrm{M}}$ and $\mathrm{K}_{1 \mathrm{~V}}$ is equal respectively to $\frac{3 \mathrm{EI}}{\mathrm{e}}$ and $\frac{G A_{\text {web }}}{\mathrm{e}}$, in which, $\mathrm{E}$ is Young's modulus of steel, $\mathrm{I}$ is the moment of inertia of the link cross-section, $G$ is the rigidity modulus of steel, and $A_{\text {web }}$ is the web area of the link section.

\subsection{Nonlinear static pushover analyses}

After defining nonlinear elements of the model, the initial nonlinear analysis is performed by calculating frame base shear. According to FEMA356, frame base shear in the concerning target level is expressed by $V=C_{1} C_{2} C_{3} C$ ${ }_{\mathrm{m}} \mathrm{S}_{\mathrm{a}} \mathrm{W}$. Seismic rehabilitated $\mathrm{RC}$ buildings due to changes in the lateral load resisting system (increase in the strength and stiffness), have a fundamental frequency less than the original case. Based on FEMA356, given that more than $75 \%$ of the total mass participates in the fundamental mode in the direction under consideration, the parabolic lateral load pattern can be used. Gravity loads combination defined in combination with seismic loads is equal to $Q_{G}=1.1\left(Q_{D}+Q_{L}\right), Q_{G}=0.9 Q_{D}$, where $Q_{D}$ is dead load effect, $Q_{L}$ is live load effect which is equal to $25 \%$ of the unreduced design live load but not less than the measured live load.

\subsection{Reliability analysis}

In this section the comparison between the seismic performance reliability analysis of original and rehabilitation frames with eccentric bracing with the vertical link by means of NLSP analysis results and the reliability methods such as Monte Carlo and Hasofer-Lind is evaluated. In Monte Carlo analysis 25, 100, 1000, 10,000 and 100,000 simulated random variables are used. The NLSP analysis is conducted by means of OpenSees software package in two PLs: life safety and collapse prevention. Concrete resistance $\left(f_{c}{ }^{\prime}\right)$, steel yield stress of bars and profiles $\left(F_{y}\right)$, beams height $(H)$, columns dimension (D) and bars area section $\left(A_{s}\right)$ are considered as random variables in this article. Limit state functions that are defined as maximum roof displacement $\left(\mathrm{g}_{\text {roof }}\right)$ and maximum inert-story displacement $\left(g_{\max }\right)$ can be expressed
Fig. 4 Moment-rotation and Shear force-shear deformation relationships of a steel link [37]
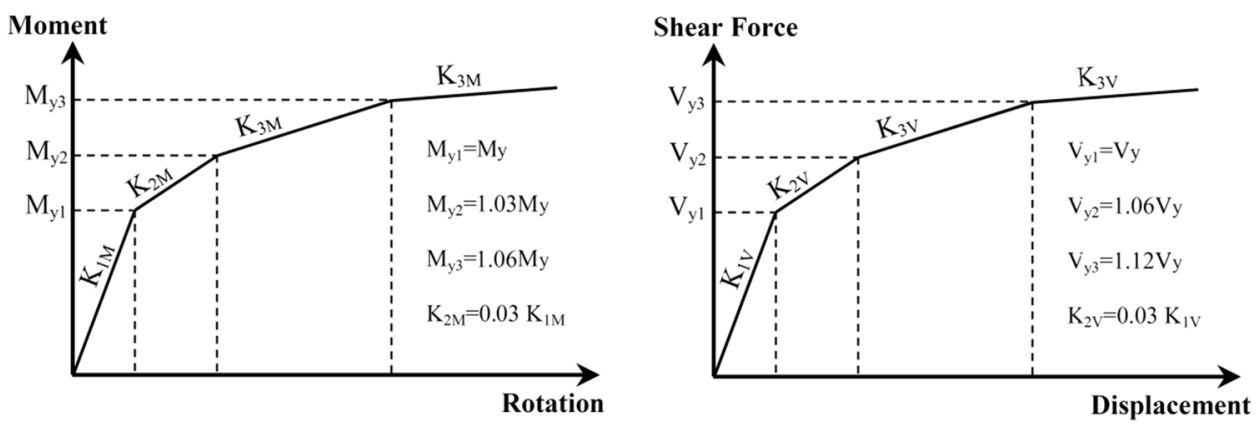
by means of different combinations in accordance with random variables values obtained from NLSP analysis. The total number of NLSP analysis is 1944. These functions are derived by statistic software called Minitab [22]. Equations (5) and (6) clearly show those limit states.

$g_{\text {roof }}\left(f_{c} ; F_{y} ; A_{s} ; H ; D\right)=\delta_{c, \text { roof }}-\delta_{\text {roof }}\left(f_{c} ; F_{y} ; A_{s} ; H ; D\right)$

$g_{\text {max }}\left(f_{c} ; F_{y} ; A_{s} ; H ; D\right)=\delta_{c ; \max }-\delta_{\max }\left(f_{c} ; F_{y} ; A_{s} ; H ; D\right)$

where the allowable displacements according to FEMA356 in original case for (LS) PL. are $\delta_{c, \max }=0.02 \mathrm{~h}_{\mathrm{s}^{\prime}} \delta_{c, \text { roof }}=0.02 \mathrm{H}$ and for (CP) PL. are $\delta_{c, \text { roof }}=0.04 \mathrm{H}, \delta_{c, \max }=0.04 \mathrm{~h}_{s^{\prime}}$. And these values in rehabilitation case for (LS) PL. are $\delta_{c, \max }=0.015 \mathrm{~h}_{\mathrm{s}^{\prime}}$ $\delta_{c, \text { roof }}=0.015 \mathrm{H}$ and for $(\mathrm{CP}) \mathrm{PL}$. are $\delta_{c, \text { roof }}=0.02 \mathrm{H}$, $\delta_{c, \max }=0.02 \mathrm{~h}_{\mathrm{s}}$. $\delta_{\text {roof }}$ and $\delta_{\max }$ represent the demand function that express in terms of nonlinear regression of random variables. In this study two types of probability of distribution in order to model the random variables are used. The characteristic of random variables in accordance with their probability distribution is shown in Table 3.

\subsection{Reliability analysis of 3 story RC frame in original case}

According to Figs. 5, 6, 7 and 8, in the Monte Carlo method by increasing the number of simulated random variables into 100,000 samples, the reliability index $(\beta)$ and probability of failure (PF) for the limit state of $\mathrm{g}_{\text {roof }}$ in (LS, CP) PLs are converged respectively in $(10,000,1000)$ and $(100,1000)$ samples with difference percentage of $(1.3 \%, 5.2 \%)$ and $(0.1 \%, 3.6 \%)$. And also the converging of $(\beta)$ and $(\mathrm{PF})$ for limit state of $g_{\max }$ in (LS, CP) PLs occur in $(10,000,10,000)$ and $(1000,1000)$ simulated samples with different percentage of $(7 \%, 0.3 \%)$ and $(2.9 \%, 2.3 \%)$. So based on the above results, more simulated samples are not needed.

By comparison between all of the simulated samples of Monte Carlo and Hasofer-Lind method, it is cleared that reliability index ( $\beta$ ) and the probability of failure (PF) in the Hasofer-Lind method have respectively larger and smaller amount than simulated samples in considered limit sates and PLs. And this shows that Hasofer-Lind overestimates the reliability index $(\beta)$ and underestimates the probability of failure (PF). The difference percentage of (PF) between Hasofer-Lind and the converged sample of Monte Carlo method for the limit state of $\mathrm{g}_{\text {roof }}$ in (LS, CP) PLs are $(24.4 \%$, $6.9 \%)$ and for the limit state of $g_{\max }$ are $(11.1 \%, 15.1 \%)$.
Table 3 Characteristics of random variables $[10,20$, 23-25, 38]

\begin{tabular}{lllll}
\hline Variables & Mean value & Deviation ratio & SD & $\begin{array}{l}\text { Probabilistic } \\
\text { distribution }\end{array}$ \\
\hline $\mathrm{fc}\left(\mathrm{kN} / \mathrm{m}^{2}\right)$ & 21,000 & 0.15 & 3150 & Normal \\
$\mathrm{Fy}\left(\mathrm{kN} / \mathrm{m}^{2}\right)$ & 300,000 & 0.107 & 32,100 & Lognormal \\
$\mathrm{As}\left(\mathrm{m}^{2}\right)$ & $2.834 \mathrm{E}-4$ & 0.04 & 0.000011336 & Normal \\
$\mathrm{H}(\mathrm{m})$ & 0.6 & 0.02 & 0.012 & Normal \\
$\mathrm{D}(\mathrm{m})$ & 0.3 & 0.02 & 0.006 & Normal \\
\hline
\end{tabular}
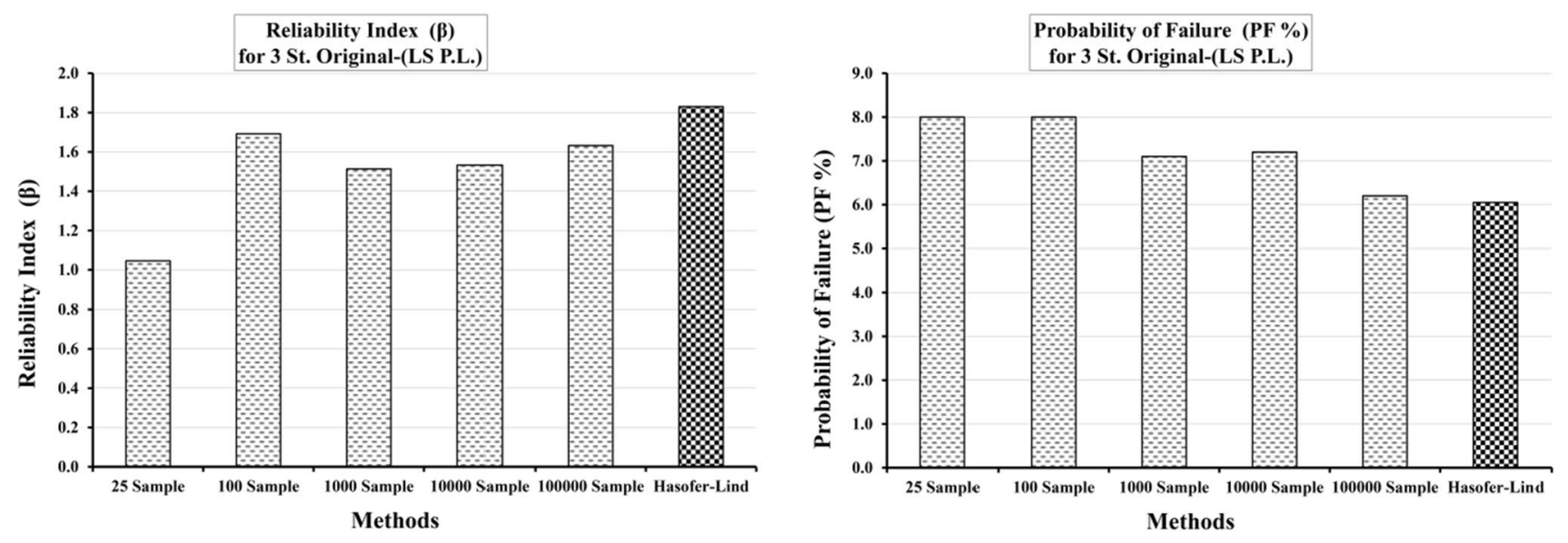

Fig. 5 Reliability analysis according to limit state $\left(g_{\text {roof }}\right)$ in (LS) PL 

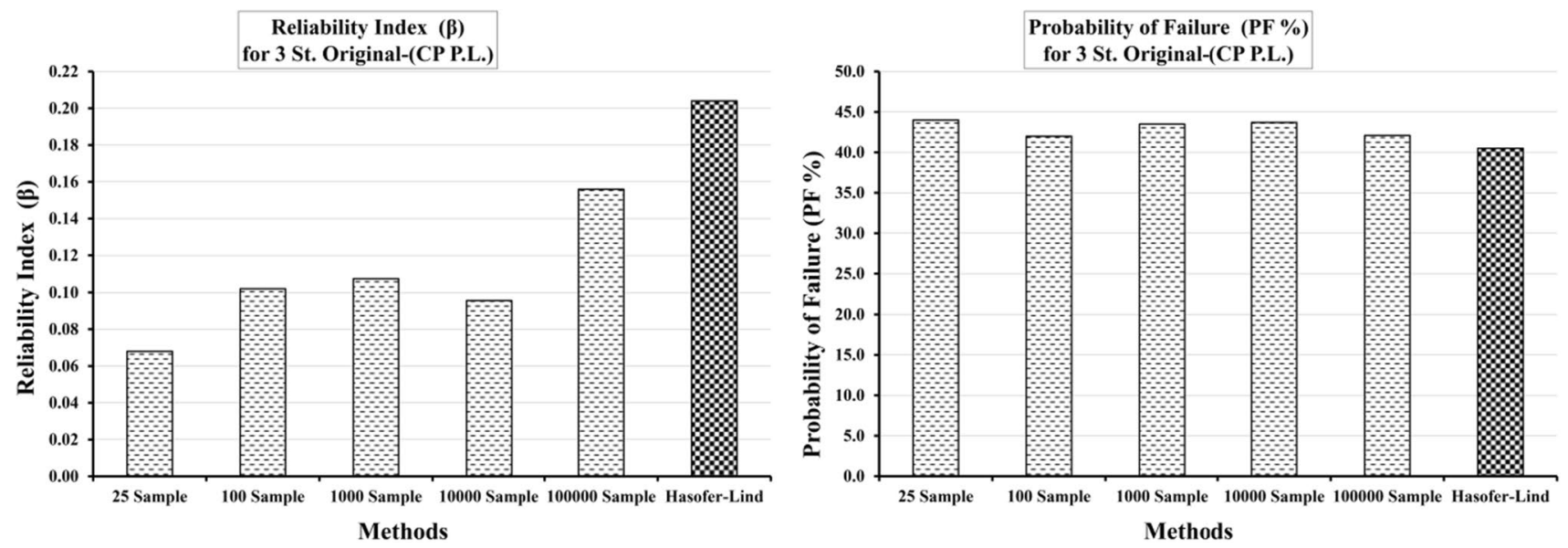

Fig. 6 Reliability analysis according to limit state $\left(g_{\text {roof }}\right)$ in (CP) PL
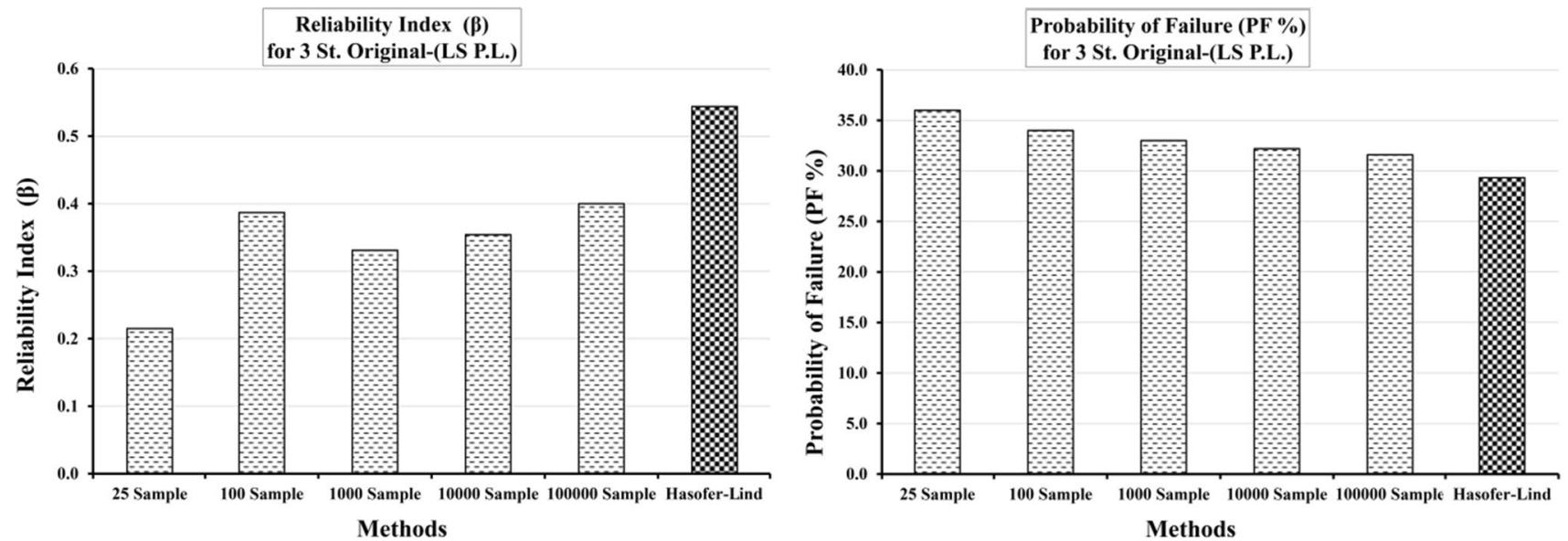

Fig. 7 Reliability analysis according to limit state $\left(g_{\max }\right)$ in (LS) PL
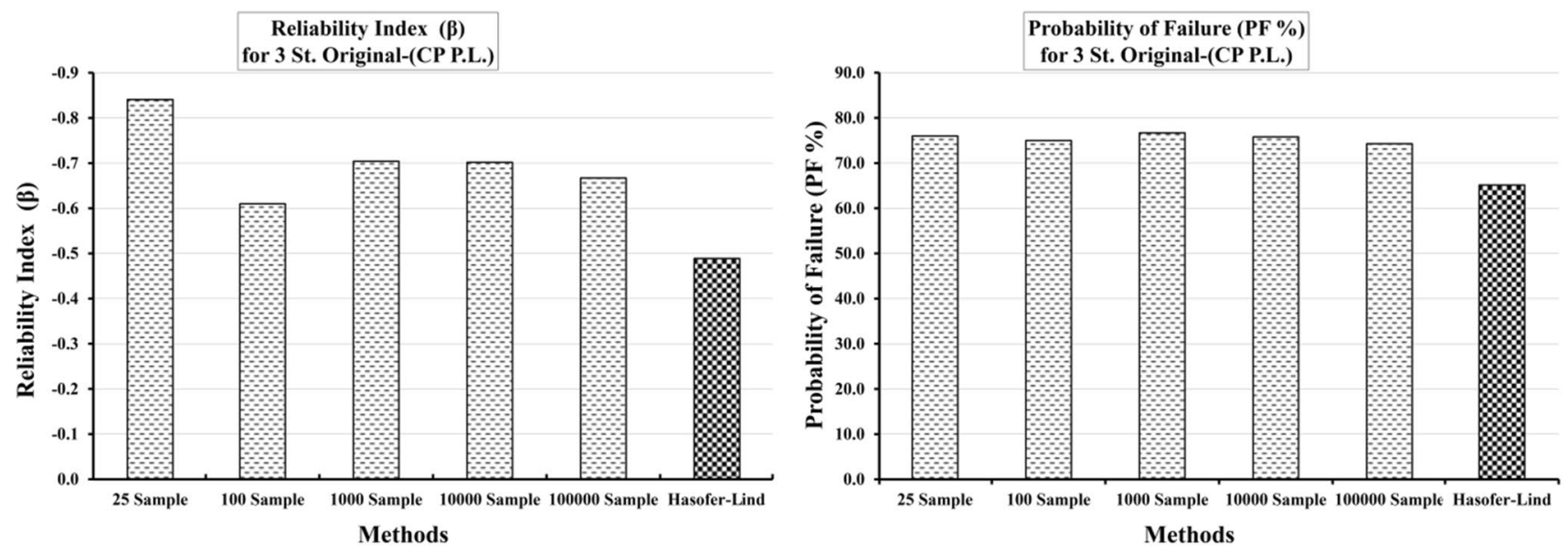

Fig. 8 Reliability analysis according to limit state $\left(g_{\max }\right)$ in $(C P) P L$ 

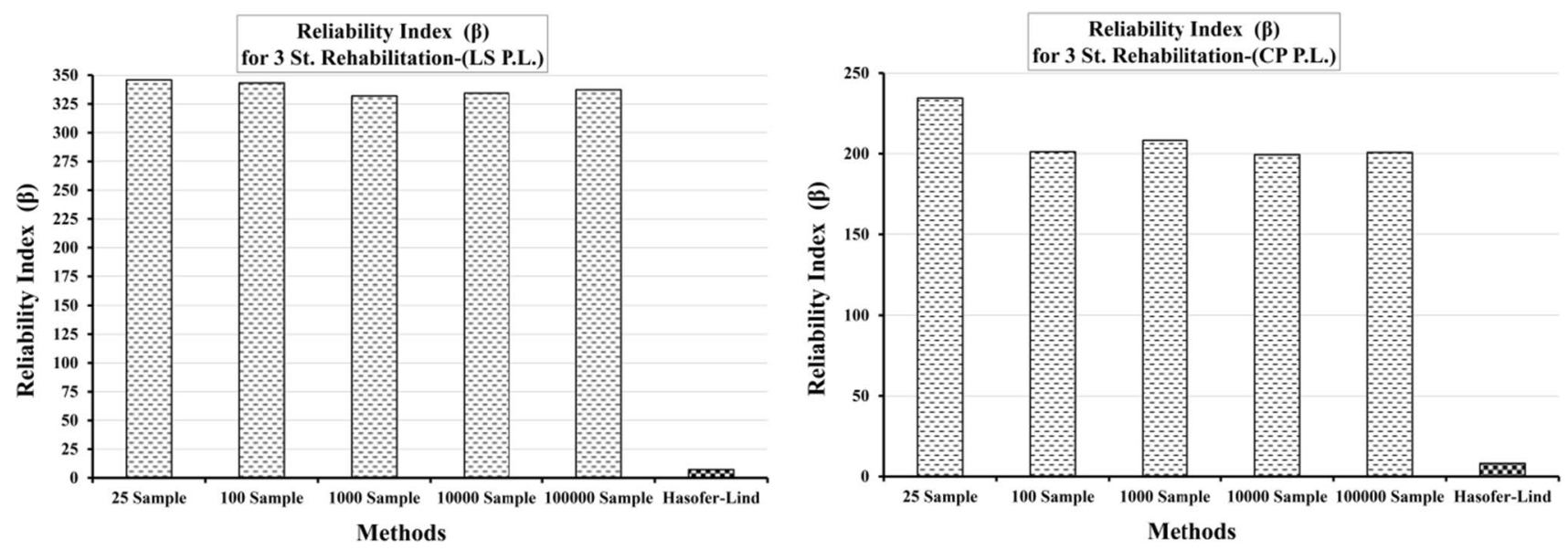

Fig. 9 Reliability analysis according to limit state $\left(\mathrm{g}_{\text {roof }}\right)$ in (LS) and (CP) PLs
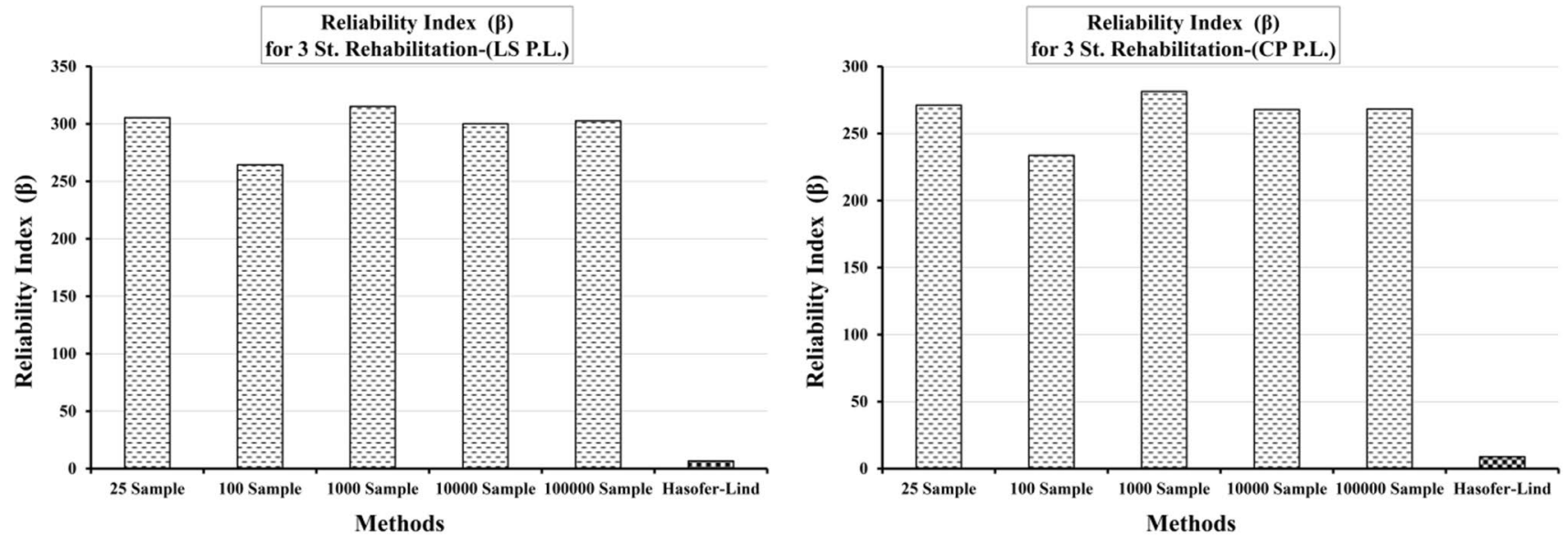

Fig. 10 Reliability analysis according to limit state $\left(\mathrm{g}_{\max }\right)$ in (LS) and (CP) PLs

\subsection{Reliability analysis of 3 story RC frame in rehabilitation case}

As it is shown in Figs. 9 and 10, the converging of $\beta$ in the Monte Carlo method, for the limit states of $\left(\mathrm{g}_{\text {roof }}\right)$ and $\left(g_{\text {max }}\right)$ in $(L S, C P)$ PLs are in $(100,1000)$ and $(10,000,10,000)$ samples with difference percentage of $(0.8 \%, 3.5 \%)$ and (4.8\%, 4.8\%).

By comparison of the results in original and rehabilitation cases, it can be concluded that the failure occurred in the original case by the negative value of limit states $\left(g_{\text {roof }}<0\right)$ and $\left(g_{\max }<0\right)$. and in the rehabilitation case safety region is concluded; $\left(g_{\text {roof }}>0\right)$ and $\left(g_{\max }>0\right)$ so in this condition the probability of failure is approximated to zero and the effectiveness of seismic performance of $\mathrm{RC}$ frame with eccentric bracing with the vertical link is clearly recognized.

The results of reliability index $(\beta)$ in rehabilitation case of 3 story frame for simulated samples are not in the specified range and have large amounts; on the other hand, the Hasofer-Lind reliability method is close to its upper limit and has a certain amount. Therefore, the overestimating of Hasofer-Lind still remains. While both methods result in zero value for the probability of failure (PF).

\subsection{Reliability analysis of 9 story RC frame in original case}

According to Figs. 11, 12, 13 and 14, in the Monte Carlo method by increasing the number of simulated random variables into 100,000 samples, $(\beta)$ and $(P F)$ for the limit state of $\mathrm{g}_{\text {roof }}$ in (LS, CP) PLs are converged respectively in $(100,000,1000)$ and $(100,000,100)$ samples with difference percentage of $(5.8 \%, 3.5 \%)$ and $(6.6 \%, 2.4 \%)$. And also the converging of $(\beta)$ and $(P F)$ for limit state of $\mathrm{g}_{\max }$ in (LS, CP) PLs occur in $(100,000,10,000)$ and $(10,000$, 100) simulated samples with different percentage of $(0.2 \%, 0.8 \%)$ and $(4.7 \%, 1.2 \%)$. The results show that by 

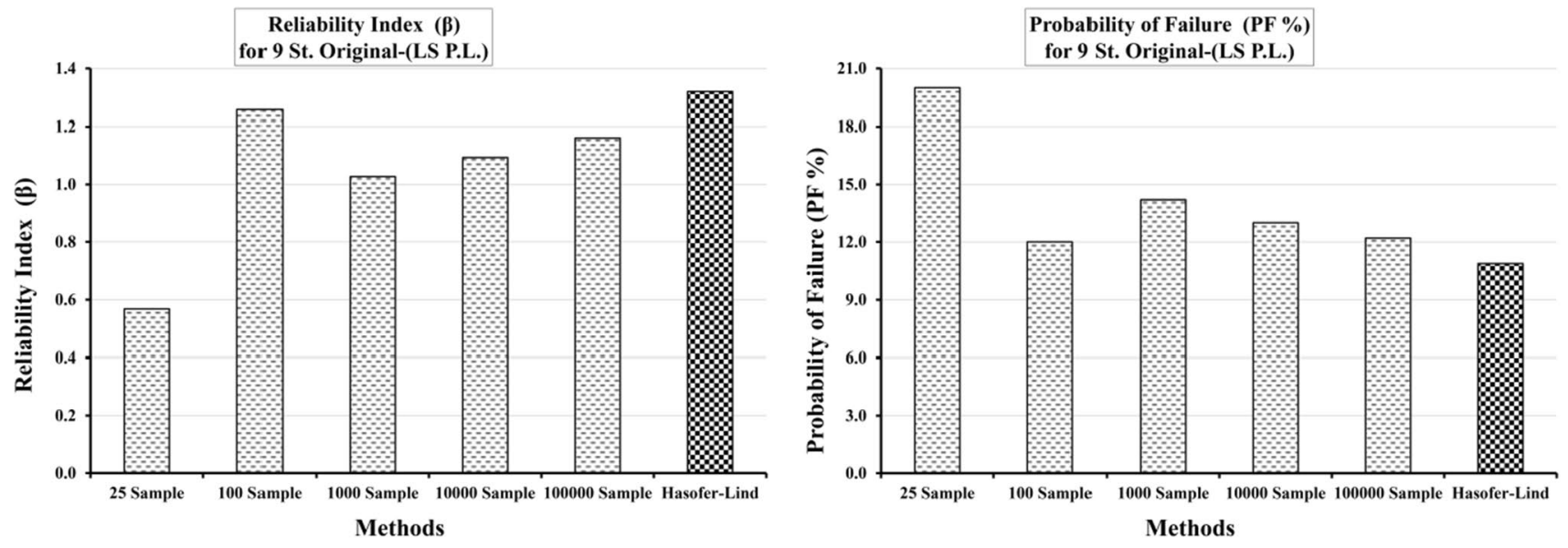

Fig. 11 Reliability analysis according to limit state $\left(\mathrm{g}_{\text {roof }}\right)$ in (LS) PL
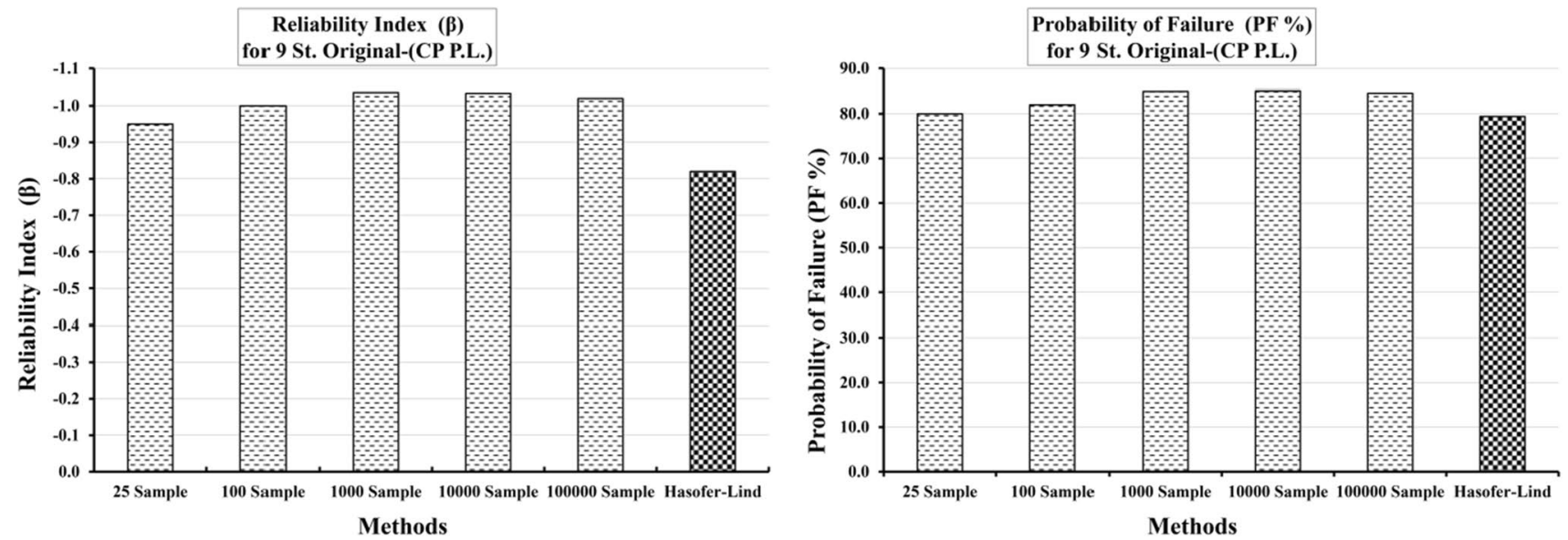

Fig. 12 Reliability analysis according to limit state $\left(\mathrm{g}_{\text {roof }}\right)$ in (CP) PL
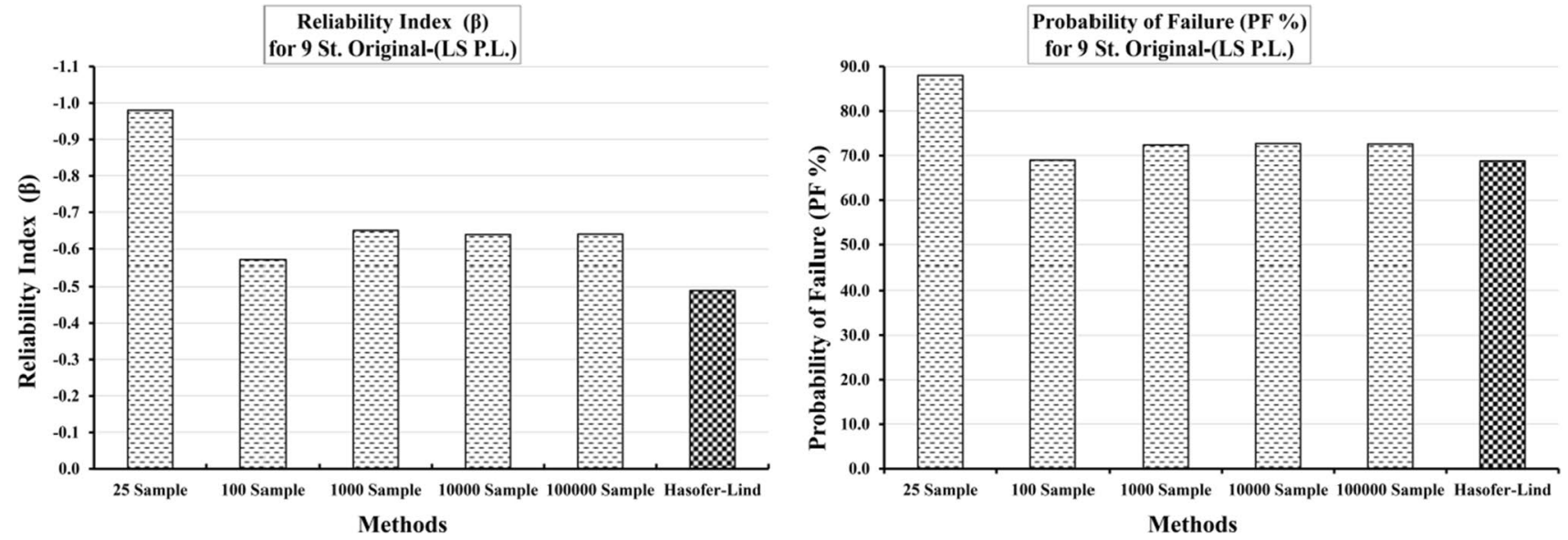

Fig. 13 Reliability analysis according to limit state $\left(g_{\max }\right)$ in (LS) PL 


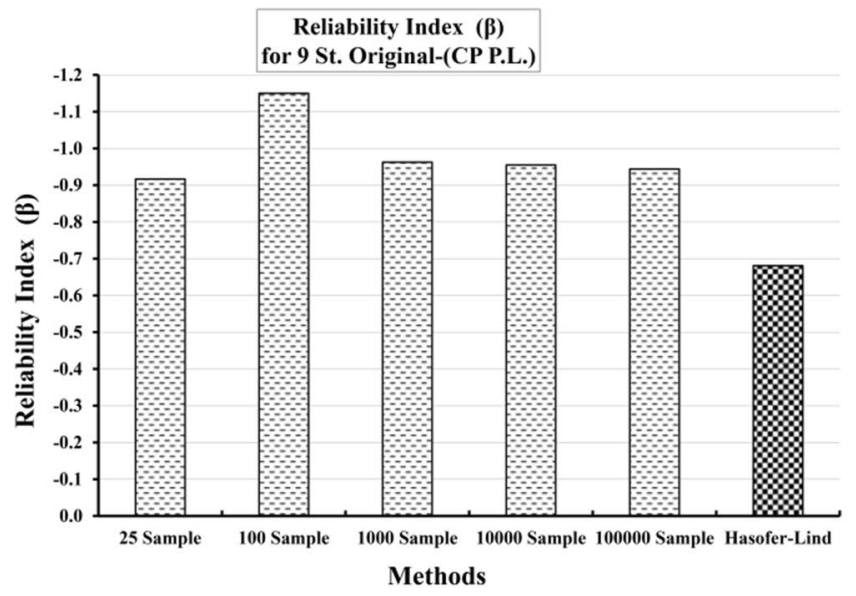

Fig. 14 Reliability analysis according to limit state $\left(\mathrm{g}_{\max }\right)$ in $(\mathrm{CP}) \mathrm{PL}$

increasing the number of stories, the required number of samples increase. It is particularly obvious that by increasing the earthquake intensity in (CP) PL. compared to (LS) PL., more simulated samples are needed.

In the 9 story frame similar to the 3-story frame, the Hasofer-Lind method over-estimates the reliability index $(\beta)$ compared to all simulated samples of the Monte Carlo method. And in both PLs for two limit states the probability of failure (PF) is underestimated by Hasofer-Lind method so that the difference percentage of (PF) between Hasofer-Lind and the converged sample of Monte Carlo method for the limit state of $\mathrm{g}_{\text {roof }}$ in (LS, CP) PLs are $(10.9 \%, 3.2 \%)$ and for the limit state of $\mathrm{g}_{\max }$ is $(5.4 \%, 14.2 \%)$. And these results show higher seismic resistance of frames expressed by Hasofer-Lind reliability analysis.

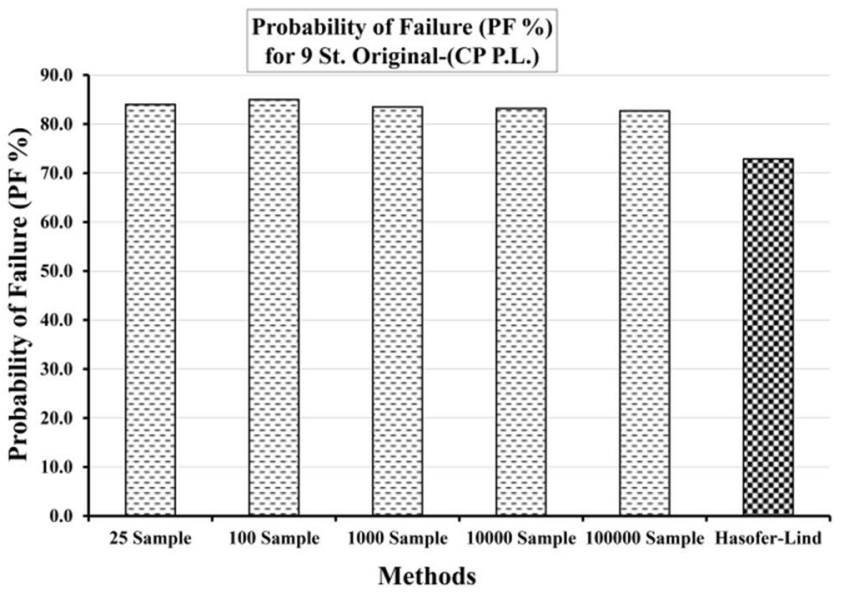

\subsection{Reliability analysis of 9 story RC frame in rehabilitation case}

According to Figs. 15, 16 and 17, in the Monte Carlo method by increasing the number of simulated random variables into 100,000 samples, $(\beta)$ for the limit state of $\mathrm{g}_{\text {roof }}$ in (LS, CP) PLs are converged respectively in $(10,000$, $100,000)$ samples with different percentage of $(1.7 \%$, $2.07 \%)$. And also the converging of ( $\beta$ ) for the limit state of $\mathrm{g}_{\max }$ in LSPL. is occurred in 10,000 simulated samples with a different percentage of $1.8 \%$, but in (CP) PL. more simulated samples are needed for attaining reasonable converge. By comparison of the results with 3 story frame, it can be concluded that by increasing the number of stories, the required number of samples increases. Similar to the previous results, also in this frame it is recognized that by increasing the earthquake intensity in (CP) PL. compared to (LS) PL., more samples should be simulated.

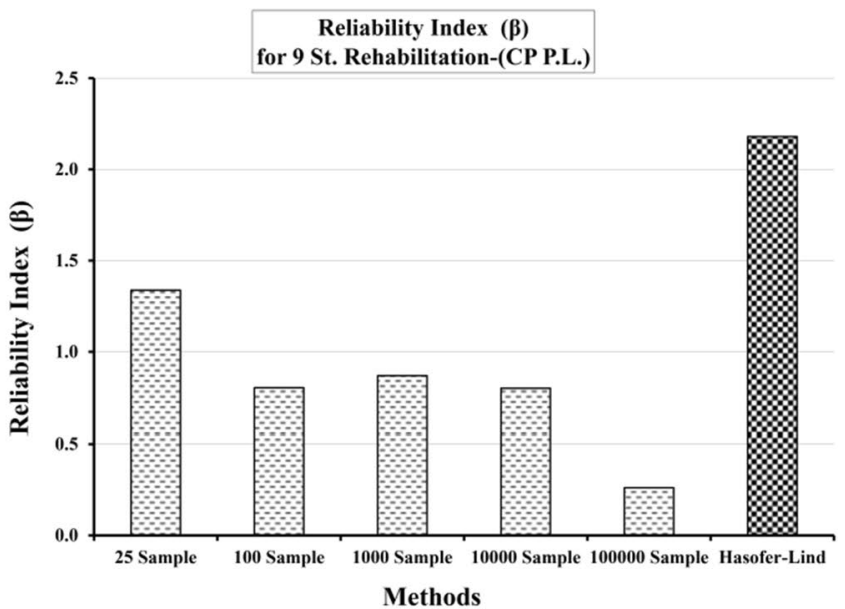

Fig. 15 Reliability analysis according to limit state $\left(\mathrm{g}_{\text {roof }}\right)$ in (LS) and (CP) PLs 

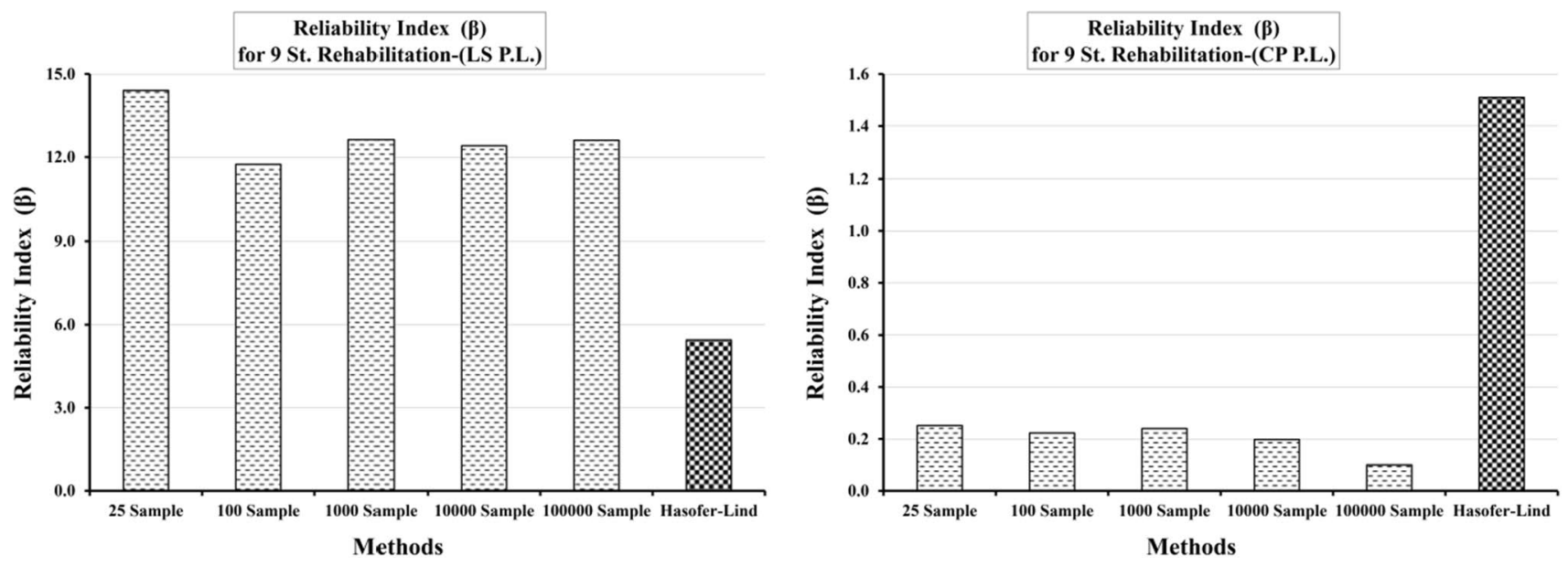

Fig. 16 Reliability analysis according to limit state $\left(\mathrm{g}_{\max }\right)$ in (LS) and (CP) PLs
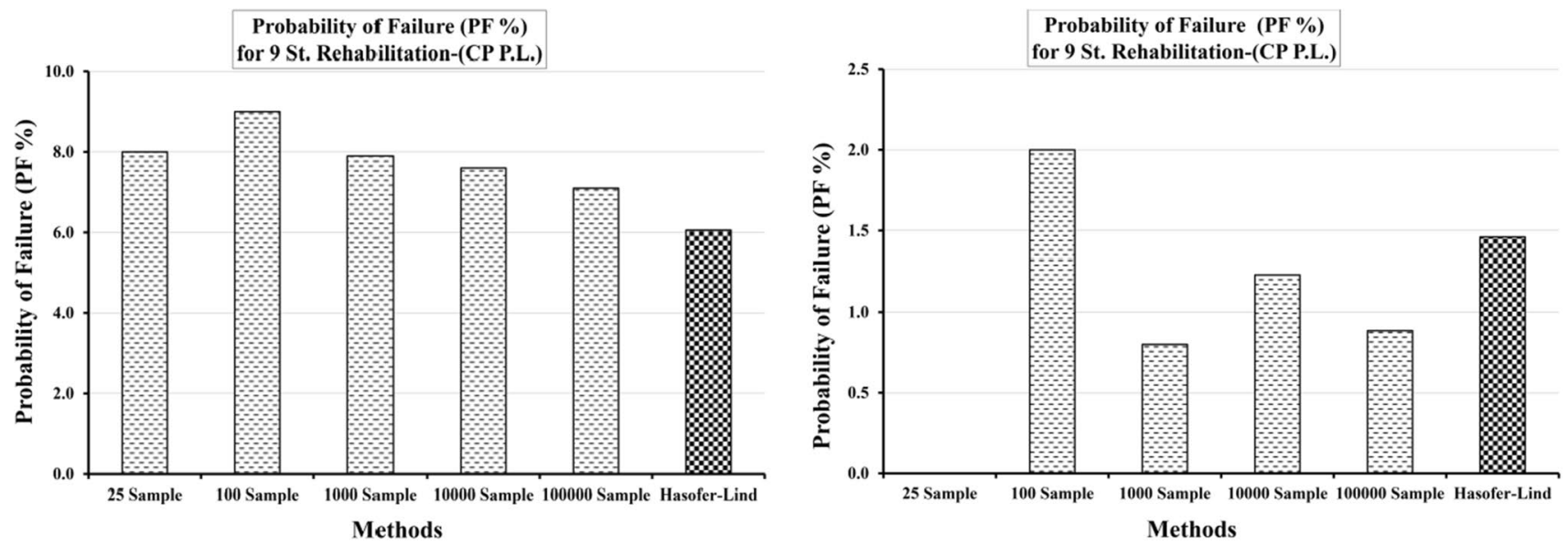

Fig. 17 Reliability analysis according to limit state (a): $g_{\max }$ and (b): $g_{\text {roof }}$ in (CP) PL

The probability of failure (PF) for the limit state of $g_{\text {roof }}$ in (CP) PL. in all samples of Monte Carlo and Hasofer-Lind method results in the range of (0-2\%), therefore, similar to the rehabilitated 3 story frame (PF) is approximated to zero. For the limit state of $g_{\max }$ in (CP) PL. the difference between the converged sample of Monte Carlo method and the Hasofer-Lind is around $20.3 \%$ and this difference shows the underestimation of (PF) in the Hasofer-Lind method and so higher resistance is concluded by this method.

As the results of the 3-story frame, it is clear that in 9 story frame the failure occurred in the original case with the condition of $\left(g_{\text {roof }}<0\right)$ and $\left(g_{\max }<0\right)$. And safety condition is declared in rehabilitation case; $\left(\mathrm{g}_{\text {roof }}>0\right)$ and $\left(g_{\max }>0\right)$ so in this condition the effectiveness of seismic performance of $\mathrm{RC}$ frame with eccentric bracing with the vertical link is clearly recognized.
For both limit states in (CP) PL. the overestimation of $(\beta)$ in Hasofer-Lind method compared to all samples of Monte Carlo is clearly expressed, and in (LS) PL. the result of $(\beta)$ according to the Hasofer-Lind method is close to its upper bound so in this case the overestimation of $(\beta)$ of this approximate method is observed.

\section{Conclusion}

In this article, the seismic performance reliability analysis of two 3 and 9 story RC frames that need rehabilitation based on the present criteria in two cases of original and rehabilitation with RC frame with eccentric bracing with the vertical link was assessed. This was presented by exact and approximate methods of reliability analysis; Monte Carlo and Hasofer-Lind based on the results 
of NLSP analysis. The NLSP analysis was done under the parabolic lateral load pattern in two (LS) and (CP) PLs. Two limit states of $\left(\mathrm{g}_{\text {roof }}\right)$ and $\left(\mathrm{g}_{\max }\right)$ were defined, and five random variables represented the variation in resistance of concrete material, bars and steel profiles yield stress, beams height, columns dimension, and also bars crosssection were introduced.

According to the reliability analysis based on the exact method of Monte Carlo with 25, 100, 1000, 10,000 and 100,000 simulated samples, it was found that the volume of evaluation was increased by raising the story of the frames so that in the 9 story frame compare to 3 story frame, more simulated samples were needed.

By comparison two reliability analysis methods applied in this study, it was determined that in both PLs., the Hasofer-Lind method had a smaller amount of $P_{F}$ and a larger amount of $\beta$ than Monte Carlo analysis. Therefore, the Monte Carlo reliability analysis method is a more conservative approach and presents a stronger seismic rehabilitation system for RC frames.

Based on the results of seismic performance reliability analysis of two 3 and 9 story RC frames in original and rehabilitation cases, it was found that the failure condition $\left(g_{\text {roof }}<0\right)$ and $\left(g_{\max }<0\right)$ was established in the original case of these frames that showed the seismic weakness of these frames according to present criteria. Hence after adding the eccentric bracing with a vertical link to these frames in order to increase their seismic performance, the results of reliability analysis showed the safe condition ( $g_{\text {roof }}>0$ ) and $\left(g_{\max }>0\right)$ of frames after seismic rehabilitation.

\section{Compliance with ethical standards}

Conflict of interest The authors confirm that they do not have any conflict of interest.

\section{References}

1. Abdelouafi EG, Abdellatif K, Mohamed BM, Francesc LA (2011) Seismic performance reliability analysis for reinforced concrete buildings. J Civ Eng Constr Technol 2(3):45-53

2. ACI Standard, ACl 318-63 (1963) American Concrete Institute, Building Code Requirements for Structural Concrete and Commentary, Edition 1963

3. Ahmadi $M$, Naderpour $H$, Kheyroddin A (2017) ANN model for predicting the compressive strength of circular steel-confined concrete. Int J Civ Eng 15(2):213-221

4. Ahmadi M, Naderpour H, Kheyroddin A, Gandomi AH (2017) Seismic failure probability and vulnerability assessment of steel-concrete composite structures. Period Polytech Civ Eng 61(4):939-950

5. Basaga HB, Kartal ME, Bayraktar A (2012) Reliability analysis of steel braced reinforced concrete frames with semi-rigid connections. Int J Struct Stab Dyn 12(5):1250037
6. Betz W, Beck JL, Papaioannou I, Straub D (2018) Bayesian inference with reliability methods without knowing the maximum of the likelihood function. Probab Eng Mech 53:14-22

7. Celarec D, Dolšek M (2013) The impact of modelling uncertainties on the seismic performance assessment of reinforced concrete frame buildings. J Eng Struct 52:340-354

8. Durucan C, Dicleli M (2010) Analytical study on seismic retrofitting of reinforced concrete buildings using steel braces with shear link. J Eng Struct 32:2995-3010

9. Elfath A (1998) Rehabilitation of nonductile reinforced concrete buildings using steel systems. Ph.D. thesis. University of McMaster University, Hamilton

10. Ellingwood B (1977) Statistical analysis of RC beam-column interaction. J Struct Eng ASCE 103:1377-1388

11. Esmaeili H, Kheyroddin A, Naderpour H (2013) Seismic behavior of steel moment resisting frames associated with $\mathrm{RC}$ shear walls. Iran J Sci Technol Trans Civ Eng 37(C):395

12. FEMA 356 (2000) Prestandard and Commentary for the seismic rehabilitation of buildings, Federal Emergency Management Agency. Edition November

13. Hadianfard MA, Razani R (2003) Effects of semi-rigid behavior of connections in the reliability of steel frames. Struct Saf 25(2):123-138

14. Haji M, Naderpour $H$, Kheyroddin A (2019) Experimental study on influence of proposed FRP-strengthening techniques on $\mathrm{RC}$ circular short columns considering different types of damage index. Compos Struct 209:112-128

15. Hasofer AM, Lind NC (1974) An exact and invariant first order reliability format. J Eng Mech Div ASCE 100(1):111-121

16. Huh J, Haldar A (2000) Reliability estimation of buildings subjected to seismic excitation. In: Proceedings of the 8th ASCE specialty conference on probabilistic mechanics and structural reliability, Notre Dame

17. Jalayer F, lervolino I, Manfredi G (2010) Structural modeling uncertainties and their influence on seismic assessment of existing RC structures. Struct Saf 32:220-228

18. Khuri Al, Cornell JA (1996) Response surfaces: designs and analyses. Marcel Dekker, New York

19. Lou YH, Durrani A, Conte J (1995) Seismic reliability assessment of existing RC flat-slab buildings. J Struct Eng 121(10):1522-1530

20. Lu R, Luo Y, Conte JP (1994) Reliability evaluation of reinforced concrete beams. Struct Saf 14:277-298

21. Marinilli M (2008) Simplified stochastic analysis of reinforced concrete frames under seismic loads. In: The 14th World conference on earthquake engineering, October 12-17, Beijing, China

22. Minitab 17.1.0.0 (2004) LEADTOOLS @ 1991-2004, LEAD Technologies, Inc.

23. Mirza SA, Hatzinikolas M, McGregor JG (1979) Statistical descriptions of strength of concrete. J Struct Eng ASCE 105:1021-1036

24. Mirza SA, McGregor JG (1979) Variations in dimensions of reinforced concrete members. J Struct Eng ASCE 105:751-765

25. Mirza SA, McGregor JG (1979) Variability of mechanical properties of reinforced bars. J Struct Eng ASCE 105:921-937

26. Moradi E, Naderpour H, Kheyroddin A (2020) An experimental approach for shear strengthening of RC beams using a proposed technique by embedded through-section FRP sheets. Compos Struct 238:111988

27. Murao O, Yamazaki F (1999) Development of fragility curves for buildings based on damage data due to Hyogoken-Nanbu earthquake. In: Proceedings of the Asia-Pacific symposium on structural reliability and its applications, Taipei

28. Naderpour $\mathrm{H}$, Mirrashid M (2019) Shear failure capacity prediction of concrete beam-column joints in terms of ANFIS and GMDH. Pract Period Struct Des Constr 24(2):04019006 
29. Naderpour H, Mirrashid M (2019) Classification of failure modes in ductile and non-ductile concrete joints. Eng Fail Anal 103:361-375

30. Naderpour H, Kheyroddin A, Amiri GG (2010) Prediction of FRPconfined compressive strength of concrete using artificial neural networks. Compos Struct 92(12):2817-2829

31. Naderpour H, Rafiean AH, Fakharian P (2018) Compressive strength prediction of environmentally friendly concrete using artificial neural networks. J Build Eng 16:213-219

32. Nowak AS, Collins KR (2012) Reliability of structures. McGraw-Hill Higher Education, Civil Engineering Series

33. Ogawa N, Yamazaki F (1999) Image interpretation of building damage due to the 1995 Hyogoken-Nanbu earthquake using aerial photographs. In: Proceedings of the Asia-Pacific symposium on structural reliability and its applications, Taipei

34. OpenSees Version 0.3.1 (2002) Open system for earthquake engineering simulation. Pacific Earthquake Engineering Research Center, University of California, Berkeley

35. Papadrakakis M, Papadopoulos V, Lagaros ND (1996) Structural reliability analysis of elastic-plastic structures using neural networks and Monte Carlo simulation. Comput Methods Appl Mech Eng 136:145-163

36. Ramadan T, Ghobarah A (1995) Analytical model for shear-link behavior. J Struct Eng ASCE 121(11):1574-1580

37. Richards PW (2004) Cyclic stability and capacity design of steel eccentrically braced frames. Ph.D. dissertation, Department of Structural Engineering, University of California, San Diego, La Jolla

38. Tso WK, Zelman IM (1970) Concrete strength variation in actual structures. ACl J 87:981-988

39. Wang C, Zhang H, Li Q (2019) Moment-based evaluation of structural reliability. Reliab Eng Syst Saf 181:38-45

40. Xu J, Kong F (2019) Adaptive scaled unscented transformation for highly efficient structural reliability analysis by maximum entropy method. Struct Saf 76:123-134

Publisher's Note Springer Nature remains neutral with regard to jurisdictional claims in published maps and institutional affiliations. 